\title{
Self-reported exercise and longitudinal outcomes in cystic fibrosis: a retrospective cohort study
}

\author{
Joseph M Collaco*, Scott M Blackman, Karen S Raraigh, Christopher B Morrow, Garry R Cutting \\ and Shruti M Paranjape
}

\begin{abstract}
Background: Cystic fibrosis (CF) is characterized by recurrent respiratory infections and progressive lung disease. Whereas exercise may contribute to preserving lung function, its benefit is difficult to ascertain given the selection bias of healthier patients being more predisposed to exercise. Our objective was to examine the role of self-reported exercise with longitudinal lung function and body mass index (BMI) measures in CF.

Methods: A total of 1038 subjects with CF were recruited through the U.S. CF Twin-Sibling Study. Questionnaires were used to determine exercise habits. Questionnaires, chart review, and U.S. CF Foundation Patient Registry data were used to track outcomes.

Results: Within the study sample $75 \%$ of subjects self-reported regular exercise. Exercise was associated with an older age of diagnosis $(p=0.002)$, older age at the time of ascertainment $(p<0.001)$, and higher baseline $\operatorname{FEV}_{1}(p=0.001)$, but not CFTR genotype ( $p=0.64)$ or exocrine pancreatic function $(p=0.19)$. In adjusted mixed models, exercise was associated with both a reduced decline in $\operatorname{FEV}_{1}(p<0.001)$ and BMI Z-score $(p=0.001)$ for adults, but not children aged $10-17$ years old.

Conclusions: In our retrospective study, self-reported exercise was associated with improved longitudinal nutritional and pulmonary outcomes in cystic fibrosis for adults. Although prospective studies are needed to confirm these associations, programs to promote regular exercise among individuals with cystic fibrosis would be beneficial.
\end{abstract}

Keywords: Cystic fibrosis, Lung function, FEV 1 , Body mass index, Exercise

\section{Background}

Cystic fibrosis (CF) is a life-limiting single gene disorder caused by mutations in the cystic fibrosis transmembrane conductance regulator gene (CFTR) leading to progressive lung function decline. As half of the variation in CF lung disease is secondary to non-genetic factors $[1,2]$, examining the role of environmental factors is critical in reducing the morbidity and mortality associated with CF. Although a number of factors have been shown to have an impact on lung function in CF, including secondhand smoke exposure [3-5], health insurance [6-9], household income [10], adherence [11], air pollution [12], and ambient temperature [13], only two of these are readily modifiable: secondhand smoke and

\footnotetext{
* Correspondence: mcollac1@jhmi.edu Eudowood Division of Pediatric Respiratory Sciences, Johns Hopkins Medical Institutions, David M. Rubenstein Building, 200 North Wolfe Street, 21287 Baltimore, MD, USA
}

adherence. Another potential modifiable factor to improve outcomes may be exercise.

There have been a number of well designed randomized controlled trials of exercise among individuals with CF to determine the effects of exercise on lung function and nutritional status. These trials, lasting from 1 week to 3 years, have employed aerobic exercise, resistance training, or a combination of both. Some studies have demonstrated benefits to $\mathrm{FEV}_{1}[14,15]$, and some have seen promising trends $[16,17]$, while others have not seen any benefit [18-20]. Similarly, some studies have seen a benefit to FVC [15-18], while others have not $[14,19,20]$. The mixed results of these studies may be related to the differing ages of participants or the differing types and duration of exercise regimens utilized, although it should be noted that no difference in $\mathrm{FEV}_{1}$ was seen in a 1 year trial of resistance training vs. aerobic training in CF. [21] Another reason for the differing 
results may be statistical power, as these studies range from 13 to 65 participants. A hypothetical study with 30 cases and 30 controls with an assumed baseline $\mathrm{FEV}_{1}$ percent predicted rate of decline of $2.0 \pm 1.0 \%$ per year would only have a statistical power of $62 \%$ to detect a difference of $0.5 \%$ decline per year. However, a recent larger prospective study of exercise in children with cystic fibrosis $(n=212)$ did see an association between increased habitual physical activity and a reduced decline in $\mathrm{FEV}_{1}$ [22].

Many individuals with CF also have exocrine pancreatic insufficiency leading to lifelong malabsorption and poor weight gain. Thus a potential concern is the increased caloric expenditure resulting from exercise. Limited data suggest that individuals with CF expend more energy with exercise than do healthy controls independent of baseline resting energy expenditures [23]. The results are mixed for the effects of exercise on nutritional status in randomized controlled trials; at least one study has seen benefits for body mass index (BMI) or ideal weight-for-height for certain types of exercise [14], one study observed a trend towards benefit [16], and other studies have not seen any benefit [18-20].

In the absence of a larger randomized controlled trial, we examined longitudinal respiratory and nutritional outcomes in a large, well characterized sample of individuals with cystic fibrosis. Exercise was self-reported representing a real-world scenario of asking patients whether they participate in regular exercise. Using data from the CF Twin-Sibling Study, we hypothesized that exercise would be associated with a reduced decline in lung function $\left(\mathrm{FEV}_{1}\right)$ and improved nutritional status (body mass index Z-scores) over time for individuals who exercised compared to those who did not. Secondary analyses included assessing the prevalence of wheezing in individuals who exercised versus those who did not as we hypothesized that individuals reporting wheezing with exercise would be less likely to participate in exercise. Given our study sample size, we were also able to examine whether specific subgroups of subjects were more likely to benefit from exercise (i.e., males vs. females, children vs. adults, etc.).

\section{Methods}

\section{Study sample}

All subjects were part of the CF Twin-Sibling Study ( $\mathrm{n}=1038$ individuals in 575 families) and were recruited from CF centers in the United States $(\mathrm{n}=952)$, Australia $(\mathrm{n}=48)$, Israel $(\mathrm{n}=24)$, and United Kingdom (Scotland) $(\mathrm{n}=14)$ between 2000 and 2013 on the basis of having $\mathrm{CF}$ and having a twin or sibling with CF. The CF TwinSibling Study was designed to assess genetic and environmental modifiers of clinical outcomes in CF. Written consent was obtained from all subjects and the study was approved by the Johns Hopkins University Institutional Review Board (Protocol \#NA_00035659). Baseline questionnaires were obtained upon enrollment and included (cross-sectional) questions on whether exercise was routinely undertaken. English-language questionnaires included questions (Additional file 1: Table S1) on whether various types of exercise were undertaken (i.e., competitive, recreational, or both), which was tabulated for subjects $\geq 10$ years of age. The questionnaires used are not validated and not age-specific; caregivers routinely completed questionnaires for children less than 18 years of age.

\section{Demographics}

Age for each subject was defined by the date the questionnaire was completed. Race/ethnicity was self-defined with subjects reporting any non-white ancestry defined as non-white. Pancreatic sufficiency was defined by genotype data $(\mathrm{n}=911)$ as having one or more "pancreatic sufficient" mutations, and by clinical data $(\mathrm{n}=106)$ where genotype data was indeterminate or not available. We were unable to ascertain pancreatic function status for 21 subjects.

\section{Outcome ascertainment}

The presence or absence of wheezing with exertion was defined by self-report. Pulmonary function test and body mass index outcome data was collected through chart review with data supplementation from the U.S. Cystic Fibrosis Foundation Patient Registry. Longitudinal data from non-U.S. locations were not necessarily available. All raw $\mathrm{FEV}_{1}$ (liters) measurements were converted into $\mathrm{FEV}_{1}$ percent predicted values as defined by the U.S. CF Foundation $[24,25]$. Baseline $\mathrm{FEV}_{1}$ for a subject was defined as the average $\mathrm{FEV}_{1}$ of all measurements obtained the 12 months preceding or after the exercise questionnaire date. Change in lung function over time was calculated from linear regression of all $\mathrm{FEV}_{1}$ percent predicted measurements in the 5 years following questionnaire completion for subjects with a minimum of 4 $\mathrm{FEV}_{1}$ values taken over a period of no less than 2 years. Body mass indices were converted into Z-scores using CDC reference equations [26]. Baseline BMI Z-score and change in BMI Z-score were calculated in a similar manner to $\mathrm{FEV}_{1}$.

\section{Statistical analysis}

Differences in baseline characteristics and clinical outcomes were compared using $T$-tests for continuous variables and Pearson's chi-square for categorical variables. To assess the effect of self-reported exercise on longitudinal changes in lung function while accounting for confounders, we employed mixed-effects regression modeling for longitudinal repeated measures with unstructured 
covariance and random effects for intercept and slope. For longitudinal effects, we only assessed subjects over the age of 10 years based on when rates of exercise participation stabilized (Figure 1). Baseline $\mathrm{FEV}_{1}$, sex, age of diagnosis, and age of questionnaire completion were included as potential confounders as these variables differed between those who reported exercising and those who did not (Table 1). All models used a dependent variable of $\mathrm{FEV}_{1}$ percent predicted consisting of all $\mathrm{FEV}_{1}$ measurements obtained over 5 years following the time of ascertainment of exercise status $(t=0)$. The independent variables were time since ascertainment, exercise status, and a time-exercise interaction term. Exercise status was defined as no exercise $=0$ and any exercise $=1$ for the any exercise models and as no competitive exercise $=0$ and any competitive exercise $=1$ for the competitive exercise models. All adjusted models included the covariates of baseline $\mathrm{FEV}_{1}$ percent predicted age at diagnosis, age at $t=0$, and sex. We tested whether different subgroups of the study sample (females, adults, and subjects with reduced lung function) had different changes in lung function with exercise using time-exercisesex, time-exercise-adult (adults being $\geq 18$ years old), and time-exercise-reduced lung function (reduced lung function being baseline $\left.\mathrm{FEV}_{1}<80 \%\right)$ interaction terms. The interaction for sex (female $=1$; male $=0)$ model included a time-exercise-sex interaction term. The interaction for age $(\geq 18$ yo $=1 ;<18$ yo $=0)$ model included both the term dichotomous term for age and a time-exercisedichotomous age interaction term. The interaction for baseline $\mathrm{FEV}_{1}(\geq 80 \%=0 ;<80 \%=1)$ model included both the term dichotomous term for baseline $\mathrm{FEV}_{1}$ and a timeexercise-dichotomous $\mathrm{FEV}_{1}$ interaction term. $P$ values of less than 0.05 were considered statistically significant. Similar analyses were performed for BMI Z-scores,

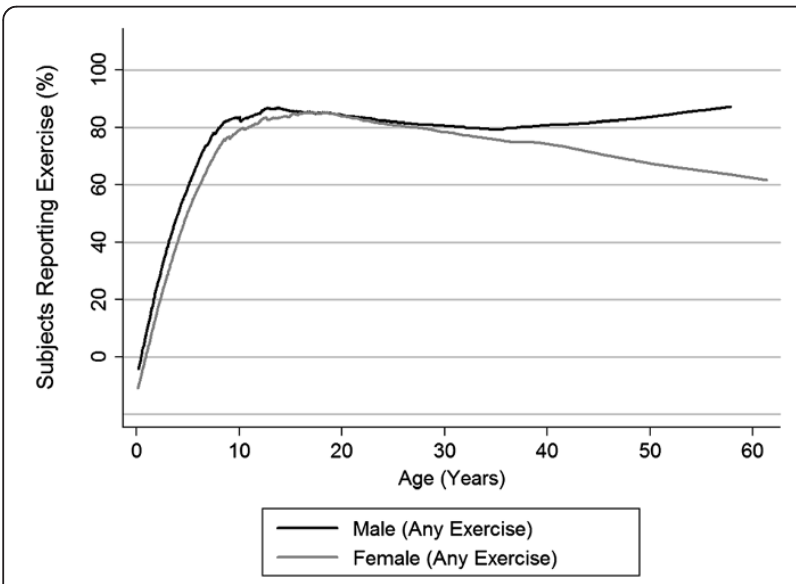

Figure 1 Exercise participation vs. age. Lowess regression of percentage of subjects reporting specific types of exercise versus age at the time of ascertainment. except both baseline BMI Z-score and baseline FEV 1 were retained as covariates. In addition, the interaction term for time-exercise-reduced BMI Z-score was defined by reduced $\mathrm{BMI}-\mathrm{Z}$ score $<0$. All analyses were performed using Stata IC 11.0 (StataCorp LP, College Station, TX).

\section{Results}

\section{Demographics}

Of the 1038 subjects in the study sample, 774 (74.6\%) reported performing exercise and (25.4\%) reported no exercise (Table 1). For the 605 subjects over the age of 10 years at the time of exercise ascertainment, 278 (46.0\%) reported participating in any competitive exercise, 235 $(38.8 \%)$ reported participating in recreational exercise only, and $92(15.2 \%)$ reported no exercise. As seen in Figure 1, participation rates in any exercise increased steadily until 10 years of age, then reached a plateau of $\sim 80 \%$, which remained relatively constant in males, but gradually decreased in females. There were no differences in the percentage of non-white individuals $(p=0.23)$ by exercise participation. There was a slight trend to more males (53\%) reporting exercise than females $(47 \% ; p=0.07)$. The group that reported no exercise had a younger age of diagnosis $(1.5 \pm 4.7$ years) than the exercise group ( $2.8 \pm 6.0$ years; $p=0.002)$; however, no differences were seen with exocrine pancreatic function status $(p=0.19)$ or CFTR genotype (frequency of F508del homozygotes) $(p=0.64)$. The group that reported no exercise had a younger age of exercise ascertainment $(10.1 \pm 11.1$ years $)$ than the exercise group $(15.0 \pm 9.6$ years; $p<0.001)$. Between countries, there were differences in the frequency of F508del homozygotes (U.S., 45.9\%; Australia, 62.2\%; Israel, 0\%; U.K., 21.4\%; $p<0.001$ ), frequency of exocrine pancreatic function (U.S., 84.2\%; Australia, 81.3\%; Israel, 66.7\%; U.K., 57.1\%; $p=0.006$ ), and age at the time of exercise ascertainment (U.S., 14.1 years; Australia, 8.4; Israel, 16.2; U.K., 8.3; $p<0.001$ ), but no other demographic differences (Additional file 1: Table S2).

\section{Respiratory outcomes}

There was no difference in the proportion of subjects who reported wheezing with exertion between those who did not routinely exercise $(22.0 \%)$ vs. those did (23.9\%)(Table 1). Those who reported exercise had a higher baseline $\mathrm{FEV}_{1}$ percent predicted $(85.6 \pm 21.5 \%)$ than those who did not $(78.0 \pm 26.7 \% ; p=0.001)$. Similar findings were seen in F508del homozygotes where those who reported any exercise had a higher mean baseline $\mathrm{FEV}_{1}(84.5 \pm 21.7 ; \mathrm{n}=283)$ compared to the no exercise group ( $73.7 \pm 27.0 ; \mathrm{n}=53 ; p=0.002)$. For the entire study sample, there were no differences in the rates of lung function decline in the 5 years following ascertainment of exercise status between those who exercised vs. those who did not. 
Table 1 Study sample demographics and clinical outcomes

\begin{tabular}{|c|c|c|c|c|}
\hline Mean \pm S.D. [range] & Entire study sample & No exercise & Any exercise & $P$ value \\
\hline $\bar{n}$ & 1038 & 264 & 774 & - \\
\hline Sex (\% male) & 51.8 & 47.0 & 53.5 & 0.07 \\
\hline \multirow[t]{2}{*}{ Race/Ethnicity (\% non-white) } & 9.2 & 11.0 & 8.5 & 0.23 \\
\hline & $(n=1036)$ & $(n=263)$ & $(n=773)$ & \\
\hline \multirow[t]{3}{*}{ Age at Diagnosis (years) } & $2.5 \pm 5.7$ & $1.5 \pm 4.7$ & $2.8 \pm 6.0$ & 0.002 \\
\hline & {$[0,52]$} & {$[0,51]$} & {$[0,52]$} & \\
\hline & $(n=1025)$ & $(n=259)$ & $(n=766)$ & \\
\hline \multirow[t]{2}{*}{ CFTR Genotype (\% F508del homozygotes) } & 45.2 & 46.4 & 44.7 & 0.64 \\
\hline & $(n=1023)$ & $(n=263)$ & $(n=760)$ & \\
\hline \multirow[t]{2}{*}{ Exocrine Pancreatic Function (\% insufficient) } & 83.3 & 85.9 & 82.4 & 0.19 \\
\hline & $(n=1017)$ & $(n=256)$ & $(n=761)$ & \\
\hline \multirow[t]{2}{*}{ Age at Ascertainment of Exercise Status (years) } & $13.8 \pm 10.2$ & $10.1 \pm 11.1$ & $15.0 \pm 9.6$ & $<0.001$ \\
\hline & {$[0.1,61.3]$} & {$[0.1,61.3]$} & {$[1.4,57.8]$} & \\
\hline \multirow[t]{2}{*}{ Wheezing Reported with Exercise (\% yes) } & 23.4 & 22.0 & 23.9 & 0.54 \\
\hline & $(n=995)$ & $(n=250)$ & $(n=745)$ & \\
\hline \multirow[t]{3}{*}{ 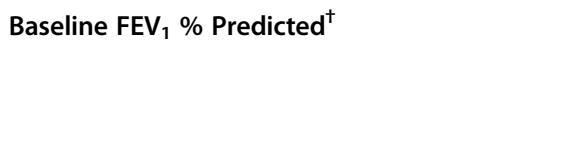 } & $84.5 \pm 22.5$ & $78.0 \pm 26.7$ & $85.6 \pm 21.5$ & 0.001 \\
\hline & {$[19.7,145.8]$} & {$[19.7,145.8]$} & {$[21.4,137.6]$} & \\
\hline & $(n=766)$ & $(n=115)$ & $(n=651)$ & \\
\hline \multirow[t]{3}{*}{ Change in $\mathrm{FEV}_{1} \%$ Predicted/Year ${ }^{\dagger+}$} & $-1.33 \pm 4.65$ & $-0.99 \pm 5.48$ & $-1.39 \pm 4.47$ & 0.44 \\
\hline & {$[-26.4,24.3]$} & {$[-26.4,23.4]$} & {$[-23.2,24.3]$} & \\
\hline & $(n=558)$ & $(n=94)$ & $(n=464)$ & \\
\hline \multirow[t]{3}{*}{ Baseline BMI Z-score $^{\dagger}$} & $-0.15 \pm 0.99$ & $-0.12 \pm 1.05$ & $-0.16 \pm 0.98$ & 0.55 \\
\hline & {$[-4.72,3.12]$} & {$[-4.06,3.12]$} & {$[-4.72,2.50]$} & \\
\hline & $(n=904)$ & $(n=207)$ & $(n=697)$ & \\
\hline \multirow[t]{3}{*}{ Change in BMI Z-score/Year ${ }^{t \dagger}$} & $-0.01 \pm 0.20$ & $0.02 \pm 0.23$ & $-0.01 \pm 0.19$ & 0.16 \\
\hline & {$[-1.02,0.83]$} & {$[-1.02,0.70]$} & {$[-0.82,0.83]$} & \\
\hline & $(n=591)$ & $(n=134)$ & $(n=457)$ & \\
\hline
\end{tabular}

${ }^{\dagger}$ All FEV 1 \% predicted values were generated using U.S. CFF guidelines. All BMI Z-scores were generated using CDC percentiles. Baseline function represents the mean of all measurements obtained within 1 year before and after the age of exercise status ascertainment.

${ }^{+t}$ Change in function represents the predicted change using linear regression and all measurements obtained 5 years after the age of exercise ascertainment for each subject. Only subjects with a minimum of 4 measurements and a minimum of 2 years of data were included.

To account for differences in baseline $\mathrm{FEV}_{1}$, differences in age at the time of exercise status ascertainment, and sex-related and age-at-diagnoses differences in exercise participation, we employed mixed model regressions including these factors as covariates. We also limited all mixed model samples to subjects $\geq 10$ years of age at exercise ascertainment as exercise participation rates appeared to plateau after 10 years of age (Figure 1). After these adjustments, we found that the baseline decline in $\mathrm{FEV}_{1}$ percent predicted per year for 389 subjects where complete data were available was $-2.03 \%$ per year (Table 2). An increase of $0.35 \%$ per year with exercise compared to the adjusted baseline $\mathrm{FEV}_{1}$ decline was observed, giving a reduced $\mathrm{FEV}_{1}$ decline of $-1.68 \%$ per year with any exercise, but this was not statistically significant $(p=0.59)$. We also tested several interaction terms to assess whether differences in $\mathrm{FEV}_{1}$ decline with exercise were observed by sex, age, or severity of lung disease, more specifically to determine if certain subgroups would be more likely to benefit from exercise. We found that exercising adults with CF ( $\geq 18$ years old) would experience a smaller decline in $\mathrm{FEV}_{1}(-0.50 \%$ /year) compared to exercising children $(10-17$ years old $)(-2.48 \% /$ year $)(p<0.001)$, suggesting that adults may receive more of a benefit than children from exercise (Additional file 1: Figure S1). A graphic depiction of average lung function decline is shown in Figure 2 for each of the three exercise groups, showing that those reporting exercise do have higher lung function at earlier ages with a decreased decline in adulthood. An interaction term for sex was not significant. 
Table 2 Change in lung function with exercise with interaction term analyses (Subjects $\geq 10$ years old)

\begin{tabular}{|c|c|c|c|c|c|c|}
\hline \multicolumn{2}{|c|}{ Models: $n=389$ subjects } & \multirow{2}{*}{$\begin{array}{l}\text { Estimated } \mathrm{FEV}_{1} \% \\
\text { at time }=0 \\
\text { without exercise* } \\
74.8\end{array}$} & \multirow{2}{*}{$\begin{array}{l}\text { Estimated } \mathrm{FEV}_{1} \% \\
\text { at time }=0 \text { with } \\
\text { exercise* }(\boldsymbol{p} \text { value) }\end{array}$} & \multirow{2}{*}{$\begin{array}{l}\text { Baseline Change } \\
\text { in } \mathrm{FEV}_{1} \% \text { per } \\
\text { year ( } \boldsymbol{p} \text { value) } \\
-2.01(0.001)\end{array}$} & \multirow{2}{*}{$\begin{array}{l}\text { Change in } \mathrm{FEV}_{1} \% \text { over } \\
\text { baseline per year with } \\
\text { exercise ( } \boldsymbol{p} \text { value) } \\
0.28(0.67)\end{array}$} & \multirow{2}{*}{$\begin{array}{l}\text { Change in } \mathrm{FEV}_{1} \% \text { over } \\
\text { baseline per year for } \\
\text { interaction ( } p \text { value) } \\
-\end{array}$} \\
\hline Any Exercise & $\begin{array}{l}\text { Unadjusted Model } \\
\text { (No Covariates) }\end{array}$ & & & & & \\
\hline & Adjusted Model & 81.7 & $81.6(0.95)$ & $-2.03(0.001)$ & $0.35(0.59)$ & - \\
\hline & $\begin{array}{l}\text { Adjusted Model + } \\
\text { Interaction for Sex }\end{array}$ & 81.9 & $81.8(0.92)$ & $-2.03(0.001)$ & $0.05(0.94)$ & $0.67(0.17)$ \\
\hline & $\begin{array}{l}\text { Adjusted Model + } \\
\text { Interaction for Age }\end{array}$ & 82.2 & $82.1(0.93)$ & $-2.03(0.001)$ & $-0.45(0.50)$ & $1.98(<0.001)$ \\
\hline & $\begin{array}{l}\text { Adjusted Model + } \\
\text { Interaction for } \\
\text { Baseline FEV }\end{array}$ & 81.6 & $81.4(0.87)$ & $-2.03(0.001)$ & $-0.10(0.88)$ & $1.08(0.028)$ \\
\hline \multirow[t]{5}{*}{$\begin{array}{l}\text { Competitive } \\
\text { Exercise }\end{array}$} & $\begin{array}{l}\text { Unadjusted Model } \\
\text { (No Covariates) }\end{array}$ & 77.9 & $85.7(0.001)$ & $-1.70(<0.001)$ & $-0.16(0.74)$ & - \\
\hline & Adjusted Model & 81.7 & $81.6(0.98)$ & $-1.64(<0.001)$ & $-0.18(0.70)$ & - \\
\hline & $\begin{array}{l}\text { Adjusted Model + } \\
\text { Interaction for Sex }\end{array}$ & 81.7 & $81.7(0.98)$ & $-1.64(<0.001)$ & $-0.28(0.61)$ & $0.22(0.73)$ \\
\hline & $\begin{array}{l}\text { Adjusted Model + } \\
\text { Interaction for Age }\end{array}$ & 81.1 & $81.1(0.93)$ & $-1.64(<0.001)$ & $-0.84(0.11)$ & $1.83(0.004)$ \\
\hline & $\begin{array}{l}\text { Adjusted Model + } \\
\text { Interaction for } \\
\text { Baseline FEV }_{1}\end{array}$ & 81.7 & $81.6(0.93)$ & $-1.65(<0.001)$ & $-0.49(0.35)$ & $0.87(0.17)$ \\
\hline
\end{tabular}

*Estimated intercepts were calculated using the regression coefficients assuming the subject was male and had the mean values for baseline FEV ${ }_{1}$ percent predicted $(80.8 \pm 22.2)$, age of diagnosis $(3.6 \pm 7.5$ years), and age at time of exercise ascertainment $(19.5 \pm 9.4$ years)( $n=389)$. The estimated FEV 1 values are not statistically different for the adjusted models owing to the adjustment for baseline FEV 1 .

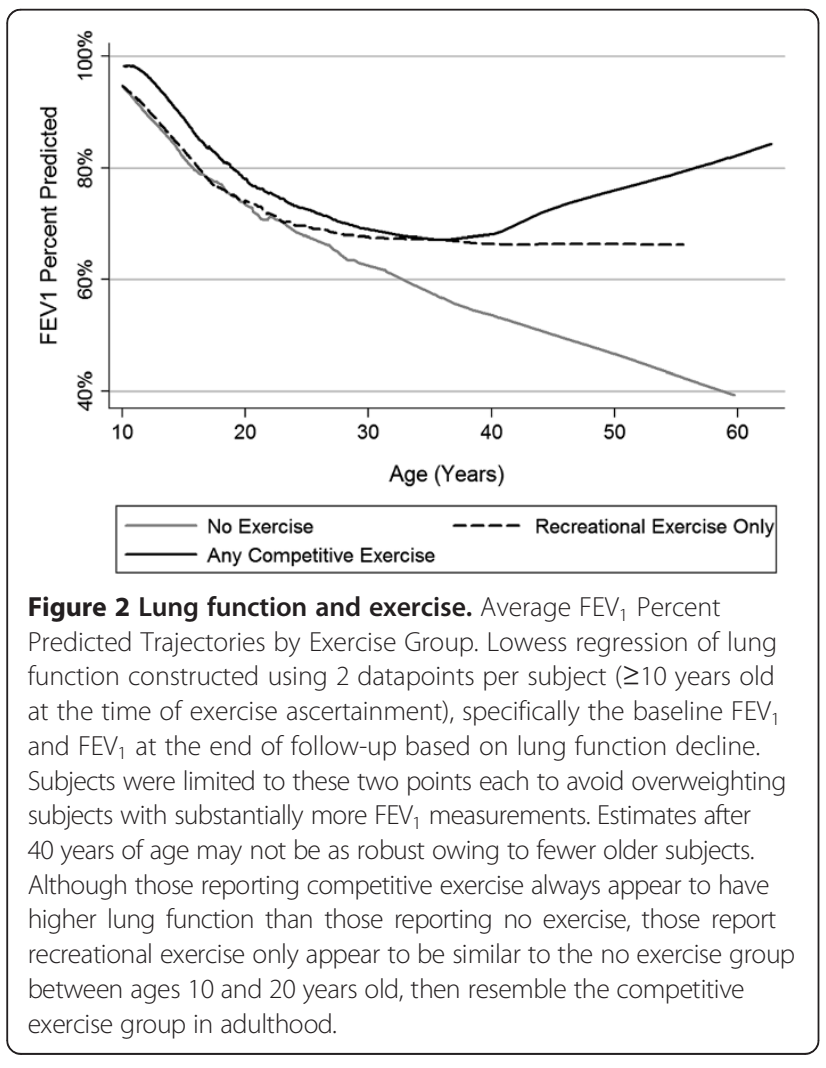

We did observe that exercising subjects with a reduced baseline $\mathrm{FEV}_{1}(<80 \%)$ experienced a smaller decline in $\mathrm{FEV}_{1}(-1.05 \% /$ year $)$ compared to exercising subjects with a baseline $\mathrm{FEV}_{1} \geq 80 \%(-2.13 \% /$ year $)(p<0.001)$. We also performed the same analysis comparing those who reported any competitive exercise vs. recreational only or no exercise to determine whether possibly more intense exercise might result in greater benefits (Table 2). No statistical reduction in the rate of $\mathrm{FEV}_{1}$ decline was observed, except as before, competitively exercising adults with CF ( $\geq 18$ years old) would experience less of decline in $\mathrm{FEV}_{1}$ compared to competitively exercising children $(10-17$ years old $)(p=0.001)$.

\section{Nutritional outcomes}

There were no differences in baseline BMI Z-score or BMI Z-score change over time between those who reported exercise, those who reported recreational only exercise, and those who reported competitive exercise. Again to account for potential confounders, we employed mixed model regressions including the baseline BMI $\mathrm{Z}$-score, baseline $\mathrm{FEV}_{1}$, sex, age at diagnosis, and age at the time of exercise status ascertainment as covariates. After these adjustments, we found that the change in BMI Z-score per year for 366 subjects $\geq 10$ years of age where 
complete data were available was not statistically different from zero $(p=0.08$; Table 3$)$. In addition, no statistically significant increase or decrease in BMI Z-score was seen with any exercise $(p=0.30)$. We also tested several interaction terms to determine whether differences in BMI Z-scores over time with exercise were observed by sex, age, or severity of lung disease. We found that exercising adults with CF ( $\geq 18$ years old) would experience $0.08 \mathrm{Z}$-score per year increase compared to exercising children $(10-17$ years old $)(p=0.001)$, again suggesting that adults may receive more of a benefit than children from exercise (Additional file 1: Figure S2). Interaction terms for sex and baseline BMI Z-score were not significant. As before we performed the same analysis comparing those who reported any competitive exercise vs. recreational only or no exercise (Table 3). In this case we found that for competitively exercising subjects with a BMI less than the 50th percentile $(B M I Z$-score $<0)$ would experience $0.06 \mathrm{Z}$-score per year increase compared to competitively exercising subjects with a BMI greater than the 50th percentile $(p=0.044)$. Interaction terms for sex and adulthood were not significant.

\section{Discussion}

In our questionnaire-based study we found that approximately $75 \%$ of individuals with cystic fibrosis reported exercising on a regular basis. Exercise rates climbed through childhood and appeared to plateau in early adolescence, suggesting that exercise patterns may become fixed during childhood for cystic fibrosis. Exercise was associated with a higher baseline lung function, but not BMI Z-score. Using mixed models with interaction terms adjusted for baseline lung function, we found that adults who reported exercising had a less rapid decline in lung function and BMI Z-scores compared to their nonexercising peers. We also observed that subjects with reduced $\mathrm{FEV}_{1}$ who perform any exercise may benefit disproportionately better than those with better lung function in terms of $\mathrm{FEV}_{1}$ decline. Likewise, we observed that subjects with reduced BMI Z-scores who perform competitive exercise may benefit disproportionately better than those with better BMI Z-scores in terms of BMI Z-score changes over time. We did not see any differences in self-reported wheezing with exertion suggesting that wheezing with exertion may not be limiting regular exercise participation or that it may be wellcontrolled with medical therapy.

Although many previous randomized control trials of aerobic exercise have not seen a significant benefit to $\mathrm{FEV}_{1}$ with exercise, we did observe a reduced decline in $\mathrm{FEV}_{1}$ for adults who exercised compared to those who did not. This may be due to the fact that short-term randomized controlled trials may be capturing the physiological response to training, whereas our study is attempting to capture the long-term effects of more continuous exercise. Similar to our study, the longest

Table 3 Change in BMI Z-scores with exercise with interaction term analyses (subjects $\geq 10$ years old)

\begin{tabular}{|c|c|c|c|c|c|c|}
\hline \multicolumn{2}{|c|}{ Models: $\mathrm{n}=366$ subjects } & \multirow{2}{*}{$\begin{array}{l}\begin{array}{l}\text { Estimated BMI } \\
\text { Z-score at time }=0 \\
\text { without exercise* }\end{array} \\
-0.36\end{array}$} & \multirow{2}{*}{$\begin{array}{l}\begin{array}{l}\text { Estimated BMI Z-score } \\
\text { at time }=0 \text { with } \\
\text { exercise* }(p \text { value })\end{array} \\
-0.30(0.65)\end{array}$} & \multirow{2}{*}{$\begin{array}{l}\begin{array}{l}\text { Baseline decline } \\
\text { in BMI Z-score } \\
\text { per year ( } \boldsymbol{p} \text { value) }\end{array} \\
-0.05(0.08)\end{array}$} & \multirow{2}{*}{$\begin{array}{l}\text { Change in BMI Z-score } \\
\text { over baseline per year } \\
\text { with exercise ( } \boldsymbol{p} \text { value) }\end{array}$} & \multirow{2}{*}{$\begin{array}{l}\text { Change in BMI Z-score } \\
\text { over baseline per year } \\
\text { for interaction ( } p \text { value }\end{array}$} \\
\hline Any Exercise & $\begin{array}{l}\text { Unadjusted Model } \\
\text { (No Covariates) }\end{array}$ & & & & & \\
\hline & Adjusted Model & -0.30 & $-0.30(0.96)$ & $-0.05(0.08)$ & $0.03(0.30)$ & - \\
\hline & $\begin{array}{l}\text { Adjusted Model + } \\
\text { Interaction for Sex }\end{array}$ & -0.29 & $-0.30(0.93)$ & $-0.05(0.08)$ & $0.02(0.48)$ & $0.02(0.36)$ \\
\hline & $\begin{array}{l}\text { Adjusted Model + } \\
\text { Interaction for Age }\end{array}$ & -0.32 & $-0.32(0.91)$ & $-0.05(0.08)$ & $0.001(0.98)$ & $0.08(0.001)$ \\
\hline & $\begin{array}{l}\text { Adjusted Model + } \\
\text { Interaction for } \\
\text { Baseline BMI Z-Score }\end{array}$ & -0.24 & $-0.25(0.92)$ & $-0.05(0.08)$ & $0.03(0.92)$ & $0.04(0.07)$ \\
\hline \multirow[t]{5}{*}{$\begin{array}{l}\text { Competitive } \\
\text { Exercise }\end{array}$} & $\begin{array}{l}\text { Unadjusted Model } \\
\text { (No Covariates) }\end{array}$ & -0.41 & $-0.18(0.021)$ & $-0.03(0.025)$ & $0.02(0.27)$ & - \\
\hline & Adjusted Model & -0.30 & $-0.31(0.72)$ & $-0.03(0.024)$ & $0.03(0.25)$ & - \\
\hline & $\begin{array}{l}\text { Adjusted Model }+ \\
\text { Interaction for Sex }\end{array}$ & -0.30 & $-0.31(0.72)$ & $-0.03(0.024)$ & $0.02(0.38)$ & $0.01(0.80)$ \\
\hline & $\begin{array}{l}\text { Adjusted Model + } \\
\text { Interaction for Age }\end{array}$ & -0.30 & $-0.31(0.69)$ & $-0.03(0.024)$ & $0.005(0.85)$ & $0.06(0.06)$ \\
\hline & $\begin{array}{l}\text { Adjusted Model + } \\
\text { Interaction for } \\
\text { Baseline BMI Z-Score }\end{array}$ & -0.24 & $-0.26(0.67)$ & $-0.03(0.023)$ & $-0.01(0.68)$ & $0.06(0.044)$ \\
\hline
\end{tabular}

*Estimated intercepts were calculated using the regression coefficients assuming the subject was male and had the mean values for baseline BMI Z-score (-0.30 \pm 0.95$)$, baseline $\mathrm{FEV}_{1}$ percent predicted $(80.3 \pm 22.0)$, age of diagnosis $(3.5 \pm 7.2$ years), and age at time of exercise ascertainment $(19.4 \pm 9.3$ years $)(\mathrm{n}=366)$. The estimated $\mathrm{BMI}$ Z-score values are not statistically different for the adjusted models owing to the adjustment for baseline BMI Z-scores. 
randomized control trial (3 years) did see a trend towards a decreased rate of $\mathrm{FEV}_{1}$ decline in those assigned to the aerobic exercise group $(-1.46 \%$ per year $)$ vs. those in the control group $(-3.47 \%$ per year; $p=0.07)$ [17]. Also, the effects of exercise may be accumulated over many years, which may be why many of the randomized controlled trials which predominantly enrolled participants $<18$ yo do not see a benefit with $\mathrm{FEV}_{1}$ or nutritional measures, and these benefits are only observed in adults in our study. An alternative hypothesis is that children may perform a different mix of aerobic vs. anaerobic activities than adults, which may have different consequences. Finally, it should be noted that Schneiderman et al. did see and association between exercise and a reduced decline in lung function among children with cystic fibrosis, which may reflect a different means of exercise ascertainment (HAES questionnaire) or differences in care within the study locations in Canada [22].

We did observe that females were less likely to report performing exercise than their male counterparts starting at 25-30 years old. Previously published crosssectional studies suggest that differences in activity levels between sexes may occur as early as pubescence [27]. This finding may contribute to sex-specific differences in survival observed in CF. [28,29] Although at least one study has reported that rates of $\mathrm{FEV}_{1}$ decline were associated with activity levels in girls, but not in boys [29], we did not see any sex-specific benefits of exercise in interaction modeling and the response to exercise may be more a function of fitness rather than gender [30]. We also did not observe any differences in exercise rates by CFTR genotype; however, CFTR genotype may play a role in fitness level independent of lung function [31].

Strengths of this study include a well characterized population of individuals with $\mathrm{CF}$ with corresponding longitudinal phenotype data. Assessing exercise participation through a yes/no question does mimic real-world clinical practice where time may limit the use of validated questionnaires for exercise participation. However, assessing exercise in this categorical manner is the primary limitation of our study and may result in an overestimate of exercise rates. In our study sample, selfreported exercise rates reached $80 \%$ in adolescence and early adulthood. This compares to the 2010 CDC on physical activity where only $64.5 \%$ of U.S. adults were physically active as defined by $\geq 150$ minutes/week of moderate-intensity activity or $\geq 75$ minutes/week of vigorous activity [32]. It is possible that self-reported rates of exercise in cystic fibrosis may also be higher if exercise is being used as a form of airway clearance as part of the regular maintenance treatment regimen, but may also represent a form of social desirability bias when answering questionnaires. For these reasons we also assessed the effects of competitive activity, which may be a less biased measure in our population as $46 \%$ of our CF subjects over the age of 10 years reported any competitive activity, which compares to $43.5 \%$ of the general population reporting being highly active, which corresponds to $\geq 300$ minutes/week of moderate-intensity activity or $\geq 150$ minutes/week of vigorous activity [32]. Nevertheless, the potential misclassification bias associated self-report of exercise may lead to being underpowered to detect the effects of exercise. We also had the opportunity to assess exercise at one point in time and our data suggests that exercise patterns may change over time, at a minimum in young children as rates of exercise increase during childhood. Our data also does not include any quantitative assessment of exercise intensity or exercise types (e.g., aerobic vs. anaerobic), which could also affect outcomes. Lastly, although we did adjust for baseline lung function within our regression models, it is still possible that we overestimated the benefits of exercise as there may be unmeasured confounders that are associated with higher baseline lung function that reduce the rate of decline.

\section{Conclusions}

In conclusion, we found that adults may have more of a benefit from regular exercise than children aged 10-17 years old, both in terms of slowing lung function decline and preserving body mass index in CF. However, as exercise patterns may be established prior to young adulthood for individuals with $\mathrm{CF}$, there may be some benefit for pediatric clinicians to promote regular exercise habits, despite the many barriers to adherence to exercise [33]. We also did not see any decline or reduced BMI Z-scores with exercise, suggesting that individuals with CF who exercise are likely able to increase their caloric intake to meet the increased expenditures with exercise. Previous studies have found that individuals with the lowest fitness levels may see the most benefits with exercise [30,34], and we did observe disproportionate benefits for those with reduced $\mathrm{FEV}_{1}$ and/or reduced BMI Z-scores. While there is a theoretical need for large prospective studies to confirm these findings for individuals with CF, we believe the longitudinal outcome benefits associated with exercise outweigh the risks.

\section{Additional file}

Additional file 1: Figure S1. Rate of $\mathrm{FEV}_{1}$ Decline in Children and Adults with and without Exercise. Figure S2: Rate of BMI Z-Score Decline in Children and Adults with and without Exercise. Table S1: Relevant Exercise Questions from CF Twin and Sibling Study Personnel Questionnaire Form. Table S2: Study Sample Demographics by Location.

\section{Abbreviations}

BMI: Body mass index; CF: Cystic fibrosis; FEV1: Forced expiratory volume in 1 second. 


\section{Competing interests}

This work was supported by grants from the Cystic Fibrosis Foundation, Gilead Sciences Inc., and the National Institutes of Health. The funders had no role in study design, data collection and analysis, decision to publish, or manuscript preparation. All authors disclose that they have no financial interests in the subject of this manuscript. The authors declare that they have no competing interests.

\section{Authors' contributions}

All authors participated in the drafting and revision of the manuscript and all authors reviewed the final version for submission. The study was designed by JMC, GRC, and SMP. Analysis was conducted by JMC, CBM, and KSR. Data results were interpreted by $\mathrm{JMC}, \mathrm{SMB}, \mathrm{GRC}$, and SMP. All authors read and approved the final manuscript.

\section{Acknowledgments}

The authors thank the patients, their families, and clinical teams participating in the Cystic Fibrosis Twin-Sibling Study. We would also like to thank the Cystic Fibrosis Foundation Patient Registry, especially Emily Knapp and Bruce Marshall.

Received: 7 June 2014 Accepted: 29 September 2014

Published: 6 October 2014

\section{References}

1. Collaco JM, Blackman SM, McGready J, Naughton KM, Cutting GR: Quantification of the relative contribution of environmental and genetic factors to variation in cystic fibrosis lung function. J Pediatr 2010, 157:802-807.

2. Stanke F, Becker T, Kumar V, Hedtfeld S, Becker C, Cuppens H, Tamm S, Yarden J, Laabs U, Siebert B, Fernandez L, Macek M Jr, Radojkovic D, Ballmann M, Greipel J, Cassiman JJ, Wienker TF, Tümmler B: Genes that determine immunology and inflammation modify the basic defect of impaired ion conductance in cystic fibrosis epithelia. J Med Genet 2010, 48:24-31.

3. Collaco JM, Vanscoy L, Bremer L, McDougal K, Blackman SM, Bowers A Naughton K, Jennings J, Ellen J, Cutting GR: Interactions between secondhand smoke and genes that affect cystic fibrosis lung disease. JAMA 2008, 299:417-424

4. Campbell PW III, Parker RA, Roberts BT, Krishnamani MR, Phillips JA III: Association of poor clinical status and heavy exposure to tobacco smoke in patients with cystic fibrosis who are homozygous for the F508 deletion. J Pediatr 1992, 120:261-264.

5. Rubin BK: Exposure of children with cystic fibrosis to environmental tobacco smoke. N Engl J Med 1990, 323:782-788.

6. Curtis JR, Burke W, Kassner AW, Aitken ML: Absence of health insurance is associated with decreased life expectancy in patients with cystic fibrosis. Am J Respir Crit Care Med 1997, 155:1921-1924

7. Schechter MS, Shelton BJ, Margolis PA, Fitzsimmons SC: The association of socioeconomic status with outcomes in cystic fibrosis patients in the United States. Am J Respir Crit Care Med 2001, 163:1331-1337.

8. Schechter MS, Margolis PA: Relationship between socioeconomic status and disease severity in cystic fibrosis. J Pediatr 1998, 132:260-264.

9. Schechter MS, McColley SA, Silva S, Haselkorn T, Konstan MW, Wagener JS: Association of socioeconomic status with the use of chronic therapies and healthcare utilization in children with cystic fibrosis. J Pediatr 2009, 155:634-639.

10. O'Connor GT, Quinton HB, Kneeland T, Kahn R, Lever T, Maddock J, Robichaud P, Detzer M, Swartz DR: Median household income and mortality rate in cystic fibrosis. Pediatrics 2003, 111:e333-e339.

11. Eakin MN, Bilderback A, Boyle MP, Mogayzel PJ, Riekert KA: Longitudinal association between medication adherence and lung health in people with cystic fibrosis. J Cyst Fibros 2011, 10:258-264.

12. Goss CH, Newsom SA, Schildcrout JS, Sheppard L, Kaufman JD: Effect of ambient air pollution on pulmonary exacerbations and lung function in cystic fibrosis. Am J Respir Crit Care Med 2004, 169:816-821.

13. Collaco JM, McGready J, Green DM, Naughton KM, Watson CP, Shields T, Bell SC, Wainwright CE: Effect of Temperature on Cystic Fibrosis Lung Disease and Infections: A Replicated Cohort Study. PLoS One 2011, 6:e27784.
14. Selvadurai HC, Blimkie CJ, Meyers N, Mellis CM, Cooper PJ, Van Asperen PP Randomized controlled study of in-hospital exercise training programs in children with cystic fibrosis. Pediatr Pulmonol 2002, 33:194-200.

15. Kriemler S, Kieser S, Junge S, Ballmann M, Hebestreit A, Schindler C, Stussi C, Hebestreit $\mathrm{H}$ : Effect of supervised training on FEV in cystic fibrosis: A randomised controlled trial. J Cyst Fibros 2013, 12(6):714-720.

16. Moorcroft AJ, Dodd ME, Morris J, Webb AK: Individualised unsupervised exercise training in adults with cystic fibrosis: a 1 year randomised controlled trial. Thorax 2004, 59:1074-1080.

17. Schneiderman-Walker J, Pollock SL, Corey M, Wilkes DD, Canny GJ, Pedder L, Reisman JJ: A randomized controlled trial of a 3-year home exercise program in cystic fibrosis. J Pediatr 2000, 136:304-310.

18. Hebestreit $H$, Kieser S, Junge S, Ballmann M, Hebestreit A, Schindler C, Schenk T, Posselt HG, Kriemler S: Long-term effects of a partially supervised conditioning programme in cystic fibrosis. Eur Respir J 2010, 35:578-583.

19. Santana SE, Groeneveld IF, Gonzalez-Saiz L, Lopez-Mojares LM, Villa-Asensi JR, Barrio Gonzalez MI, Fleck SJ, Perez M, Lucia A: Intrahospital weight and aerobic training in children with cystic fibrosis: a randomized controlled trial. Med Sci Sports Exerc 2012, 44:2-11.

20. Klijn PH, Oudshoorn A, van der Ent CK, van der Net J, Kimpen $J$, Helders PJ: Effects of anaerobic training in children with cystic fibrosis: a randomized controlled study. Chest 2004, 125:1299-1305.

21. Orenstein DM, Hovell MF, Mulvihill M, Keating KK, Hofstetter CR, Kelsey S, Morris K, Nixon PA: Strength vs aerobic training in children with cystic fibrosis: a randomized controlled trial. Chest 2004, 126:1204-1214.

22. Schneiderman JE, Wilkes DL, Atenafu EG, Nguyen T, Wells GD, Alarie N, Tullis E, Lands LC, Coates AL, Corey M, Ratjen F: Longitudinal relationship between physical activity and lung health in patients with cystic fibrosis. Eur Respir J 2014, 43:817-823.

23. Richards ML, Davies PS, Bell SC: Energy cost of physical activity in cystic fibrosis. Eur J Clin Nutr 2001, 55:690-697.

24. Wang X, Dockery DW, Wypij D, Fay ME, Ferris BG Jr: Pulmonary function between 6 and 18 years of age. Pediatr Pulmonol 1993, 15:75-88.

25. Hankinson JL, Odencrantz JR, Fedan KB: Spirometric reference values from a sample of the general U.S. population. Am J Respir Crit Care Med 1999, 159:179-187.

26. Kuczmarski RJ, Ogden CL, Guo SS, Grummer-Strawn LM, Flegal KM, Mei Z, Wei R, Curtin LR, Roche AF, Johnson C: 2000 CDC Growth Charts for the United States: methods and development. Vital Health Stat 2002, 11:1-190.

27. Selvadurai HC, Blimkie CJ, Cooper PJ, Mellis CM, Van Asperen PP: Gender differences in habitual activity in children with cystic fibrosis. Arch Dis Child 2004, 89:928-933.

28. Rand S, Prasad SA: Exercise as part of a cystic fibrosis therapeutic routine. Expert Rev Respir Med 2012, 6:341-351

29. Schneiderman-Walker J, Wilkes DL, Strug L, Lands LC, Pollock SL, Selvadurai HC, Hay J, Coates AL, Corey M: Sex differences in habitual physical activity and lung function decline in children with cystic fibrosis. J Pediatr 2005, 147:321-326.

30. Gruber W, Orenstein DM, Braumann KM, Paul K, Huls G: Effects of an exercise program in children with cystic fibrosis: are there differences between females and males? J Pediatr 2011, 158:71-76.

31. Selvadurai HC, McKay KO, Blimkie CJ, Cooper PJ, Mellis CM, Van Asperen PP: The relationship between genotype and exercise tolerance in children with cystic fibrosis. Am J Respir Crit Care Med 2002, 165:762-765.

32. CfDCa P: State Indicator Report on Physical Activity, 2010. GA: Atlanta; 2010.

33. Prasad SA, Cerny FJ: Factors that influence adherence to exercise and their effectiveness: application to cystic fibrosis. Pediatr Pulmonol 2002, 34:66-72.

34. Gruber W, Orenstein DM, Braumann KM: Do responses to exercise training in cystic fibrosis depend on initial fitness level? Eur Respir J 2011, 38:1336-1342.

doi:10.1186/1471-2466-14-159

Cite this article as: Collaco et al: Self-reported exercise and longitudinal outcomes in cystic fibrosis: a retrospective cohort study. BMC Pulmonary Medicine 2014 14:159. 